\title{
O ESTADO DE DIREITO E O BOICOTE À LIBERDADE
}

\section{Clarisse Goulart Nunes ${ }^{1}$}

RESUMO: Em filosofia política a clássica problemática entre Estado e liberdade apresenta-se como um importante e sempre atual ponto de tensão. Este artigo tem como objetivo analisar a relação entre o modelo de Estado de Direito com a liberdade. O conceito de Estado de Direito será delimitado a partir de formulação de Jeremy Waldron e o conceito de liberdade, a partir do ensaio "Dois Conceitos de Liberdade" de Isaiah Berlin. A discussão procura estabelecer uma reflexão a respeito da possibilidade de a forma de governar própria do Estado de Direito ser compreendia como uma forma de boicote à liberdade e, consequentemente, ao ideal de viver bem.

Palavras-chave: Estado de Direito; Liberdade Negativa; Liberdade Positiva; Viver bem.

\section{THE RULE OF LAW AND THE BOYCOTT OF LIBERTY}

\begin{abstract}
In political philosophy, the classic problematic between State and liberty presents itself as an important and always current point of tension. This article aims to analyze the relationship between the rule of law model and liberty. The concept of the rule of law will be delimited from Jeremy Waldron's formulation and the concept of liberty - from the essay "Two Concepts of Liberty" by Isaiah Berlin. The discussion seeks to establish a reflection on the possibility that the way of governing the rule of law can be understood as a means of boycotting liberty and, consequently, the ideal of living well.
\end{abstract}

Keywords: Rule of Law; Negative Liberty; Positive Liberty; Live Well.

\section{CONSIDERAÇÕES INICIAIS}

Moralidade, ética e política estão relacionadas, assim como as ações coletivas, as individuais e a interferência do Estado nas esferas pública e privada dos indivíduos. O espaço de atuação dos indivíduos na sociedade é mediado pela interferência da lei nas ações individuais e coletivas. Ainda que seja ponto controvertido a importância do valor da liberdade para os modelos de governar disponíveis, a liberdade em si é um valor apreciado.

Em escopos conceituais diversos, porém com certa ligação, estão os conceitos de liberdade e de bem viver. Ronald Dworkin em "Justice For Hedgehogs" (DWORKIN,

\footnotetext{
${ }^{1}$ Doutorado em andamento Filosofia - UFRGS. Mestre Filosofia - UFRGS. Graduação Direito UNIRITTER. E-mail: clarissegn@gmail.com

Programas de Pós-Graduação em Ciências Sociais e Filosofia - UNIOESTE - Rua da

Faculdade 645. Toledo - PR. CEP 85.903-000 Email: revistaalamedas@gmail.com
} 
2011) estabelece a observância a dois princípios como requisitos fundamentais para viver bem. O primeiro princípio é o do respeito próprio e o segundo o da autenticidade. Entende-se por respeito próprio a atitude de considerar a importância de viver bem. E por autenticidade a compreensão do viver bem como uma forma de vida certa para si próprio, que traz consigo a exigência pessoal de comprometimento com certos padrões de ideais balizares às nossas ações. Outros conceitos que estão relacionados a estes dois princípios apresentados são o de livre-arbítrio e liberdade.

Pode-se dizer que alguém agiu com livre arbítrio quando foi capaz de deliberar livremente a respeito da sua ação, ou seja, de tomar uma decisão fruto de reflexão. Está certo que para alguns o arbítrio nunca é livre; é sempre causado por uma combinação de fatores fora do controle do agente. Parece-nos insustentável conceber a ideia de bem viver sem aceitar o livre-arbítrio como possível. Ficamos com a argumentação desenvolvida por São Tomás de Aquino, segundo a qual a aceitação da existência do livre-arbítrio deriva da racionalidade humana, ou seja, o homem é capaz de orientar suas ações segundo a vontade, orientada ou não pela razão (TOMÁS DE AQUINO, 1984. p. 486).A questão se aprofunda quando o indivíduo requer um espaço público para atuar, ou seja, quando o agente, comprometido com o bem viver, conforma suas ações às exigências ditadas pelo Estado de Direito. Este artigo tem como objetivo analisar em qual medida o Estado de Direito constituiu um modelo de governar apto a boicotar a liberdade.

\section{ESTADO DE DIREITO}

Jeremy Waldron(WALDRON, 2008), no ensaio "The concept and the rule of law", esclarece que o conceito de "rule of law" é um conceito "multifacetado", e identifica no seu núcleo a ideia de restrições, impostas pelas normas públicas, às pessoas quanto às preferências pessoais. Neste contexto, é importante a previsibilidade, a estabilidade e a publicidade das normas. Lon Fuller (FULLER, 1969), na obra Morality of Lawdescreve quais são oito princípios internos da moralidade da lei, a observância destes princípios descreve um meio para obter um sistema legal saudável, que viabilize a fidelidade dos cidadãos ao governo. Segundo Lon Fuller(FULLER, 1969), o fracasso de um sistema legal se deve aos seguintes motivos: 


\begin{abstract}
o primeiro e o mais óbvio está no fracasso em alcançar regras, de modo que cada questão deve ser decidida de forma ad hoc, ou seja, as regras não são gerais, são criadas para resolver casos específicos. Os motivos são: a falha em divulgar, ou pelo menos disponibilizar à parte afetada, as regras que ele deve observar; o abuso da lei retroativa, que não só não pode guiar a ação, mas prejudica a integridade das regras prospectivas em vigor, uma vez que as coloca sob o impacto da mudança retrospectiva; a falha de fazer leis incompreensíveis; a promulgação de regras contraditórias ou regras que exijam conduta além das atribuições da parte afetada; introduzir mudanças tão frequentes nas regras que o sujeito não pode orientar seu ato por elas; e, finalmente, uma falha de congruência entre as regras conforme anunciadas e sua administração real (FULLER, 1969, p.39).
\end{abstract}

Dito de outra forma, para que haja um bom sistema jurídico, as leis devem ser: gerais, promulgadas publicamente, prospectivas (e não retroativas), inteligíveis, consistentes, praticáveis, estáveis, o comportamento dos oficiais devem ser conforme as leis (WALDRON, 2002, p. 154). Tendo em vista que as normas são padrões de conduta, que não só orientam mas também limitam ações humanas, influenciando a liberdade individual, os indivíduos necessitam saber, antecipadamente, quais serão as consequências de suas condutas, sejam elas conforme ou não a prescrição ditada pelo Estado de Direito.

Considerando que tanto as condutas individuais, quanto as condutas dos agentes públicos devem ser norteadas pela observância ou não das prescrições legais, é preciso destacar dois diferentes conceitos: o de Estado de Direito e o de lei. Seria formidável se houvesse coincidência entre as prescrições da lei em abstrato e a sua aplicação, ou seja, entre as decisões de cunho político-jurídico que definem o Estado de Direito e as possíveis interpretações conferidas às leis.

É na ausência desta coincidência que o cenário das decisões político-jurídicas confere descrédito à concepção do Estado de Direito, na medida em que o "Estado de Direito é um ideal frequentemente invocado quando os governos tentam conquistar seus objetivos por meio de ações arbitrárias e opressivas, ou passando por cima das normas e procedimentos estabelecidos pela legislação de seus países” (WALDRON, 2008, p. 05).

Fartos são os exemplos em que decisões de cunho político-jurídico são fundamentadas em termos obscuros e com caráter inovador. Há ausência de previsibilidade e de estabilidade nelas, tanto em caráter procedimental quanto em caráter argumentativo. Casos emblemáticos denotam tal discordância, em especial 
quando está em discussão a disputa de cargos políticos, e, de forma ainda mais "grave", na escolha de chefes de estado.

No contexto eleitoral, podemos citar, de modo exemplificativo a recontagem de votos na Flórida nas eleições nos Estados Unidos da América (EUA)no ano de 2000(WALDRON, 2002, p. 140-141). O caso refere-se à eleição entre: George W. Bush (Republicano) e Albert Arnold “Al” Gore Jr (Democrata), o presidente anterior foi Bill Clinton, que governou por 2 mandatos consecutivos. O resultado da polêmica eleição era 271vs 266 votos. Al Gore levantou a possibilidade de irregularidades na contagem de votos na Flórida (quarto estado mais populoso, ou seja, o número de votos lá apurados era decisivo para o resultado das eleições tão "apertadas") e requereu a recontagem dos votos. Al Gore tinha a maioria dos votos em todos os outros colégios eleitorais). A Suprema Corte, composta em sua maioria por Republicanos, declarou inconstitucional a recontagem. Para alguns, tal decisão foi um "legítimo golpe de Estado".

Neste caso considerar inconstitucional a recontagem de votos fragilizou o sistema democrático e o Estado de Direito. A Suprema Corte preferiu uma decisão com a "reserva" de que tal decisão não poderia ser adotada como precedente, ou seja, a corte reconheceu, a partir desta restrição, o caráter estapafúrdio de seu ato. Decisões como esta são proferidas em vários países, interpretações a respeito de procedimentos e entendimentos que são alterados sem qualquer previsibilidade e fundamentação de cunho jurídico. Dentre outros aspectos que poderiam ser analisados, é pertinente considerar o exercício da função dos tribunais superiores em resolver conflitos de natureza política. A controvérsia deste tema está presente desde sua origem, até mesmo na concepção clássica aristotélica, a quem se atribui a criação do Estado de Direito, sem saber exatamente como definir este termo. Em Aristóteles, é possível extrair posições diferentes quando se trata de situações "políticas", ou seja, a relação entre observância à lei em geral e em casos políticos comporta tratamento excepcional(WALDRON, 2002, p. 140-141).

Como se sempre fosse necessária uma "dose extra" de discricionariedade às decisões judiciais quando versarem sobre assuntos políticos, como se fosse plenamente aceitável (ou até mesmo necessária) um grau de incerteza neste campo. Está certo que existem divergências quanto à interpretação dada a concepção aristotélica neste assunto, 
a partir da frase enigmática: "a lei é a razão não afetada pelo desejo". Alguns compreendem que não se deve conferir discricionariedade pessoal aos juízes, outros argumentam que deve haver fé na virtude do Poder Judiciário, ou confiança na lei. Parece então que a relação entre lei e razão é especialmente afetada quando se trata de decisões de cunho político. É razoável compreender que as estruturas legais devam facilitar o exercício da razão (WALDRON, 2002, p. 142), ou seja, que se espera a racionalidade nas decisões fundamentadas na lei. A partir desta expectativa é compreensível que os indivíduos não queiram ser governados por estado que permita decisões arbitrárias, em especial quando se trata de assuntos políticos, ainda que o mais comum seja ver decisões políticas motivadas por interesses pessoais.

Importante é a contribuição de Herbert L. A. Hart, na obra "The Concepto of Law” (HART, 2011), que caracteriza as decisões que estão fora da moldura da legalidade como sendo decisões extrajurídicas, deste modo, Hart não aceitaria o uso do termo decisões político-jurídico, uma vez que tais decisões estão fora da moldura da lei elas não podem ser consideradas jurídicas.Para Hart, os casos difíceis são decididos a partir da escolha do juiz, não havendo somente uma resposta para cada um deles, e sim mais de uma resposta "correta" para tanto(HART, 2011, p. 165), ou seja, os casos difíceis abrem espaço para uma solução extrajurídica, pois a interpretação não pode eliminar incertezas e o silogismo jurídico serviria apenas para os casos de simples solução.

Esta solução extrajurídica comporta dois importantes pontos de discussão com relação a qual fundamento assenta a atuação discricionária do juiz: o primeiro deles é considerar a falta de objetividade da solução quando baseada algo que não sejam as regras; e o segundo é compreender que o julgador usará parâmetros pessoais, ou seja, ele irá solucionar o caso concreto de acordo com os seus entendimentos a respeito da questão. Deste modo, o panorama que estabelece é de incerteza, de ausência de clareza e previsibilidade (próprios do Estado de Direito) os quais refletem no modo de agir dos indivíduos, em especial no que se refere à liberdade.

\section{LIBERDADE E ESTADO DE DIREITO}


A conceituação de liberdade e as perspectivas sobre a qual este problema será abordado é estabelecida a partir do artigo "Two Concepts of Liberty", de Isaiah Berlin, publicado em 1969 (BERLIN, 1969). Segundo Berlin, os problemas no campo da política sempre ocorrerão, ainda que possa ser tentador pensar na substituição de homens por máquinas para soluciona-los, na ilusão de que possam ser resolvidos com base na técnica e não em "interesses políticos", isso não vai ocorrer. Por mais coerente que possa ser é utópico crer que questões políticas, sobre problemas sociais, possam ser resolvidas com base em soluções racionais ou técnicas.Diante desta impossibilidade, Berlin alerta para o perigo da ausência de críticas às ações políticas e considera a importância do pensamento político na compreensão dos movimentos sociais.

Berlin aponta como questão política central a relação entre obediência e coerção: "Por que eu deveria (ou alguém) obedecer a mais alguém? Por que não devo viver como quero? Devo obedecer? Se eu desobedecer, posso ser coagido? Por quem, e em que grau, e em nome de quê e por causa de quê?" Para responder a estas perguntas Berlin diferencia liberdade negativa de positiva, que de forma sucinta pode ser apresentada na seguinte formulação: liberdade negativa pode ser definida como a ausência de obstáculos, de impedimentos ou restrições; enquanto liberdade positiva refere-se a possibilidade de agir de forma a concretizar os objetivos fundamentais do indivíduo. (BERLIN, 1969).

Esta distinção não é apenas conceitual na medida em que expressa ideias políticos rivais. A defesa da liberdade é algo incontroverso, a controvérsia estabelece-se entre as duas liberdades, bem como quanto ao grau de liberdade. Ian Carter (CARTER, 2019)aponta que a defesa da liberdade negativa corresponde ao ideal do liberalismo político, sobre este ponto de vista, para haver o favorecimento da liberdade individual deve haver fortes limitações no poder do Estado. Aqueles que criticam essa posição defendem que a realização da liberdade pode depender da intervenção estatal, argumentando pela defesa da liberdade positiva, compreendida como a busca por autodeterminação e autorrealização.

É oportuna a diferença entre os dois conceitos de liberdade negativa e positiva levando-se em conta a distinção entre fatores externos e internos que as influenciam. Enquanto na liberdade negativa os teóricos se interessam em qual grau de interferência externa os grupos ou indivíduos sofrem; na liberdade positiva, interessa quais fatores 
internos afetam o grau de autonomia dos indivíduos ou grupos. A partir desta distinção, poder-se-ia pensar que um filósofo político deveria se dedicar à liberdade negativa, enquanto a psicologia ou a filosofia moral à liberdade positiva. Carter considera essa separação precipitada, pois a filosofia política se ocupa de ação política, e da questão: “É possível o Estado promover a liberdade positiva dos cidadãos em seu nome?”. E se seria desejável que o Estado fizesse isso. (CARTER, 2019).

A promoção da liberdade positiva envolve referência a uma concepção do eu como racionalmente autodeterminante. Nesse sentido, a liberdade dos indivíduos de atingir a autodeterminação racional, apesar das restrições externas e internas de irracionalidade, má informação ou autoconhecimento equivocado. Aqueles que argumentam pela defesa da liberdade positiva compreendem os objetivos do agente não como uma questão de preferência, ou seja, não como "o impulso do mero apetite", mas como o que realmente é do interesse do agente. Ao tratar sobre autonomia, geralmente relacionam este termo com a liberdade positiva, mas "autonomia" também pode se referir a uma capacidade de governar a si mesmo, uma condição de autogoverno, um ideal ou uma questão de autoridade moral. A capacidade de ser autônoma depende de fatores como educação, informação e capacidade de refletir, avaliar alternativas e agir de acordo com as próprias escolhas. A condição de autonomia envolve satisfazer as próprias preferências, em vez de satisfazê-las pelos outros. Envolve alcançar ativamente os objetivos, em vez de apenas desfrutar do bem-estar. A autonomia também envolve aspectos como autodomínio, individualidade, autenticidade, integridade, autocontrole, iniciativa e responsabilidade. (HAUSAMNet al., 2017).

Já a promoção da liberdade negativa envolve a esfera externa de ação do agente, a partir dos limites de interferência do Estado. Promover a liberdade negativa é promover a existência de uma esfera de ação dentro da qual o indivíduo é soberano e dentro do qual ela pode realizar seus próprios projetos, sujeita apenas à restrição de que respeita as esferas dos outros.

Está certo que esfera de ação individual não poderia ser ilimitada, segundo Berlin, por duas razões: porque seria um caos a ausência de limites; e porque a liberdade dos mais fortes sufocaria a dos mais fracos, pois as atividades humanas não estão harmonizadas. Os valores dos objetivos de justiça, felicidade, cultura, segurança, certo 
grau de igualdade, devam ser equacionados para garantir a liberdade, sob pena de esses valores sacrificarem a liberdade.

Os limites à esfera da ação individual são fornecidos pela lei. Saber qual deve ser a "medida", o "tamanho" ou "grau" deste limite, qual dever ser o limite mínimo de interferência da lei na liberdade dos indivíduos perpassa pela compreensão da máxima, segundo a qual "A liberdade de uns deve depender da restrição de liberdade de outros"(BERLIN, 1969).

Jeremy Waldron, no artigo "Why Law - Efficacy, Freedom, or Fidelity?" (WALDRON, 1994), relaciona, considerando também sobre outros aspectos, o Estado de Direito com o respeito à liberdade e propõe-se à reflexão acerca dos benefícios de ser fiel (de obedecer) à lei, uma vez que a lei representa uma forma de restrição. Neste artigo, Waldron analisa a argumentação apresentada por Lon Fuller (FULLER, 1969) a respeito da obediência dos denominados princípios internos da moralidade, no que se relaciona à adoção do Estado de Direito como um meio eleito para governar por intermédio de regras. São definidos como princípios internos da moralidade: "os princípios da generalidade, promulgação, prospectividade, clareza, não-contradição, praticabilidade, constância e congruência entre a ação oficial e a regra declarada", os quais devem ser observados para que o estado alcance a fidelidade à lei por parte de seus governados.

A questão que se quer especular é de qual modo este modelo de governar, definido como Estado de Direito, é um instrumento capaz de viabilizar a liberdade positiva, ou em qual medida para a concretização da liberdade positiva, impõe-se a ausência de fidelidade à lei. Adotando-se uma argumentação mais forte, em qual medida o Estado de Direito constitui-se como modelo apto a boicotar a liberdade positiva. Vamos nos propor a responder a esta questão enfrentando o argumento a partir dos seguintes passos: ponto de partida: a sociedade está organizada em um "modelo" de Estado de Direito, este é um bom modelo? O que este modelo de estado tem produzido: decisões político-jurídico de "qualidade"? É possível fidelidade à lei quando os princípios internos moralidade são cotidianamente afrontados? A liberdade positiva é "importante" para o Estado de Direito? Haveria outro meio de governar que não fosse seguindo o modelo de Estado de Direito? 
Consideramos que a delimitação do que seja o Estado de Direto é conceito multifacetado, do qual se pode extrair algumas características. Destas três características citadas: previsibilidade, estabilidade e publicidade, nenhuma delas é cumprida quando se trata de decisões político-jurídica, ou seja, o modelo de Estado de Direito, tanto os modelos baseados em leis ou precedentes judiciais, a "promessa" do modelo de Estado de Direito não é cumprida. A ponto de o Estado de Direito ser

(...) um ideal frequentemente invocado quando os governos tentam conquistar seus objetivos por meio de ações arbitrárias e opressivas, ou passando por cima das normas e procedimentos estabelecidos pela legislação de seus países (WALDRON, 2008, p. 5).

Os exemplos dessas ações arbitrárias e opressivas, são fartos na história de países pelo mundo inteiro, repercute nas respostas das duas próximas questões. Sob a égide do Estado de Direito decisões de cunho político-jurídico chancelam a afronta dos princípios estabelecidos por este "mesmo" Estado de Direito, ou seja, o Estado de Direito estabelece regras que ele mesmo viola quando decide casos políticos. Tais violações repercutem nas respostas as três questões posteriores. Talvez este modelo de governar até fosse um bom modelo, se fosse seguido e se não produzisse afronta aos princípios que ele mesmo estabelece. Então, qual é a finalidade de seguir apostando num modelo que é frequentemente traído pelo ele próprio?

Poderíamos nos questionar se o ponto de controvérsia é modelo de governar ou a sociedade, poderíamos considerar a análise bem engendrada por Hanah Arendt a respeito da perda da esfera pública. A completa extinção entre privado e público, a submersão de ambos a esferado social. Na era moderna há a confusãodos limites entre o privado e o público, ao mesmo tempo a alteraçãodo significado dos dois termos e a sua importância para a vida do indivíduo e do cidadão, ao ponto de torná-los quase irreconhecíveis (ARENDT, 2008).

\footnotetext{
A polisera para eles(os gregos)o espaço político por excelência destinado ao exercício da liberdade, enquanto a esfera da vida privadaera um eespaço prépolítico responsável pela manutenção das necessidades. O que diferenciava a polis do lar era o fato denapolis o homem estar entre "iguais", livre das necessidades da vida e ao mesmo tempo fazendo uso de suasingularidade através do discurso e da ação(ARENDT, 2008).
} 
Esta análise é importante porque a cidade da Grécia Antiga era vista como um espaço de sociabilidade, de discussão, no qual buscava-se o bem da coletividade, os cidadãos inseridos no espaço público sentiam-se parte das decisões públicas. Em uma sociedade como a dos gregos, ainda que a democracia de poucos comporte conhecidas críticas, a fidelidade à lei era influenciada, talvez até determinada, por este envolvimento com as decisões públicas. Ainda assim, esta sociedade produziu uma decisão de cunho jurídico-político que guarda semelhança com tantas outras ao longo da história.

O julgamento de Sócrates retrata o ethos da sociedade grega, Sócrates aceita a sentença que lhe é imposta não por reconhecer ela como justa e sim por reconhecer que ela é fruto do entendimento da sociedade na qual ele se insere. Esta sociedade era também governada por um modelo de Estado de Direito, que, desde sua origem, atenta contra a liberdade.

É pertinente trazer à discussão a argumentação desenvolvida por Jeremy Waldron no artigo "Why Law - Efficacy, Freedom, or Fidelity?”. Ao analisar a relação entre a obediência dos princípios internos da moralidade, próprio do Estado de Direito, o autor defende a ideia de que tais princípios promovem um ambiente social que possibilita às pessoas organizarem suas vidas, planejando e agindo livremente, por intermédio da lei. Aponta para a importância de a justiça social viabilizar que as pessoas sejam "agentes livres". Waldron considera que para a teoria política é preciso equilibrar outros valores sociais com a liberdade.

No entanto, segue o autor argumentando que orespeito à liberdade envolve questões complexas, às vezes, o respeito à liberdade pode levar a políticas e escolhas sociais que estejam em desacordo com o Estado de Direito. Ele inicia com o chamado ponto de vista liberal segundo o qual a causa da liberdade pode, por vezes, envolver a intervenção governamental e a gestão da economia que de uma forma exclui as formas, os limites, os procedimentos e as garantias tradicionalmente associado à lei. Waldron compara a garantia da liberdade para a classe trabalhadora é diferente da garantia aos empresários capitalistas. Enquanto para a classe trabalhadora "bastaria" garantir vagas de emprego; para os empresários capitalistas tais medidas poderiam causar impactos conflitantes com seus interesses. Do mesmo modo ocorreria para garantir a liberdade 
para outros segmentos sociais que dependem da "generosidade" do estado. Está certo que a liberdade envolve sacrifícios de valores ligados à legalidade, ainda assim, ela pode não estar ligada de forma hegemônica no modelo do Estado de Direito(WALDRON, 1994, p.4).

A questão que persiste é compreender como o Estado de Direito, ou o modo de organização estatal instituído desta forma, viabiliza ou não a liberdade individual. Waldron traz à tona concepção de Jonh Stuart Mill na obra "On Liberty” (MILL, 1859), na qual Mill esclarece que a "ordem social" é inerentemente hostil à liberdade, e apresenta como contraponto a posição de Fuller, para quem as formas institucionais (legais) são essenciais para a liberdade em si (WALDRON, 1994, p.4).Note-se que é controvertido compreender a liberdade individual como um valor para o Estado de Direito. Para alguns a liberdade possui um "preço" alto demais, e para outros sequer há possibilidade de consenso a respeito do como a liberdade possa ser exercida em sociedade.

É interessante que ao relacionar a obediência aos princípios internos da moralidade com a viabilidade da liberdade individual,Waldorn, esclarece que para as ações governamentais deve haver outro padrão de funcionamento, ou seja, que os princípios internos da moralidade não são adequados para todos os fins do exercício do poder do estado (WALDRON, 1994, p. 272-273). Causa estranheza compreender como ações governamentais estariam "liberadas" de obedecer aos princípios internos da moralidade, considerando-se que tais princípios são amplos, ainda que as consequências das ações governamentais sejam peculiares mostra-se difícil sustentar que elas devam ser obedecidas pelos cidadãos e não pelas ações governamentais.

E esta estranheza é a que se verifica na prática, o modelo de Estado de Direito estabelece regras de obediência geral, mas que são excepcionadas quando se trata de ações governamentais. Inegável que ao aceitar este panorama, a fidelidade à lei resta prejudicada. Como o indivíduo irá se sentir compelido à obedecer as regras, em sacrifício próprio (seja existencial, seja material) sabendo que este sacrifício deve ser cumprido somente pelos particulares e, quando o estado for guiar suas ações, elas não sofrerão tais restrições.

Sabe-se que a moderna teoria dos direitos humanos nasce neste panorama de abuso de direito por parte dos Estados, ou seja, quando o estado nacional viola direitos 
humanos de seus cidadãos outra estado (internacional) é chamando para proteção individual. Exemplos de estados tirânicos não são raros, o que torna esta concepção tão alarmante, modelos de estado de direito que sacrificam não só a liberdade individual, mas, antes disso, a dignidade.

\section{CONSIDERAÇÕES FINAIS}

A importante conclusão que se presente apresentar a partir da reflexão em tornodos temas da eficácia, liberdade e fidelidade à lei é colocar em dúvida a eficácia do modelo de governar por regras. As questões sobre liberdade, autoridade, legitimidade política, a razão pela qual as pessoas obedecem às leis e cooperam com as instituições que não estão dispostas a apoiar 'aquilo que as pessoas valorizam', não podem ser estabelecidas a priori. Tais razões são verificadas empiricamente, ou seja, não se pode determinar, a priori, que o modelo "definido" como Estado de Direito, traga mais vantagens do que outros meios aos cidadãos(WALDRON, 1994, p. 272-273).O modo como o modelo de Estado de Direito lida com as liberdades, compreendidas neste termo tanto a negativa como a positiva, exige muitas vezes que os indivíduos atuem de forma contrária aos limites fornecidos. Se o modelo de Estado de Direito deveria oferecer segurança jurídica e estabilidade, as quais poderiam incentivar a concretização do ideal de liberdade e, em certa medida, de bem viver. Cada vez que a segurança jurídica e a estabilidade das decisões judicias, em especial aqueles que envolvem questões políticas, ofendem tais preceitos a esfera da ação individual é atingida e os ideias do Estado de Direito boicotam a liberdade dos indivíduos.

\section{REFERÊNCIAS BIBLIOGRÁFICAS}

ARENDT, Hannah. A condição humana. Editora Forense Universitária, Rio de Janeiro. 2007.

BERLIN, Isaiah. 'Two concepts of liberty', 1969. In I. Berlin, Four Essays on Liberty, London: Oxford University Press. New ed. in Berlin 2002.

CARTER, Ian, "Positive and negative liberty". The Stanford Encyclopedia of Philosophy (Winter 2019 Edition), Edward N. Zalta(ed.), Disponível em: 
[https://plato.stanford.edu/archives/win2019/entries/liberty-positive-negative/]. Acesso em: 08 de abr. 2019.

DWORKING, Ronald. “Justice for hedgehogs”. Harvard University Press. Cambridge. 2011.

DWORKING, Ronald. "Taking rights seriously". Harvard University Press. Cambridge. 1977

FULLER, Lon L. The morality of law. London, Yale University Press. 1969.

HART, Herbert L. A. The concept of law. Oxford University Press. Oxford. 1961.

HAUSMAN, Daniel, Michael McPherson, and Debra Satz. Economic Analysis, Moral Philosophy, and Public Policy. Third Edition. New York, NY: Cambridge University Press, 2017.

MILL, John, Stuart. On liberty. Batoche Books: Kitchener, Ontário. 2001

TOMÁS DE AQUINO. Suma TEOLÓGICA. Volume II, questão 83, p. 486. 1984.

WALDRON, Jeremy. Is the rule of law an essentially contested concept (In Florida). Law and Philosophy, In the Wake of Bush v. Gore: Law, Legitimacy and Judicial Ethics, Vol. 21, No. 2, pp. 137-164. 2002.

WALDRON, Jeremy. The concept and the rule of law. Georgia Law Review. New York University School of Law, v 43, n 1. fall 2008.

WALDRON, Jeremy. Why Law - Efficacy, Freedom, or Fidelity? Law and Philosophy, Kluwer Academic Publishers. 13, 259-284. 1994. 